\title{
Ultrasonic Sensor-Based Automated Water Dam Shutter
}

\author{
Benjamin Kommey, Seth Djanie Kotey, Daniel Opoku \\ Kwame Nkrumah University of Science and Technology, Kumasi, 00233, Ghana
}

\section{ARTICLE INFORMATION}

Received: November $15^{\text {th }}, 2019$

Revised: January $13^{\text {th }}, 2020$

Available online: March $30^{\text {th }}, 2020$

\section{KEYWORDS}

Dam, Gate, Water, Shutter, Microcontroller.

\section{CORRESPONDENCE}

Phone: +233501500954

E-mail: bkommey.coe@knust.edu.gh

\section{A $\quad$ B $\quad \mathbf{S}$ T $\mathbf{R}$ A $\mathbf{C}$ T}

\begin{abstract}
Monitoring the level of water in dams is necessary to ensure optimal operation and safety. Water level monitoring is normally done manually by a full-time operator. This results mostly in a waste of water due to the inability of the operator to accurately determine the quantity of water to release from the dam gate. In this paper, we have presented the design of a system to automatically open and close dam gates based on the level of water in the dam. The system is based on a low-cost microcontroller and an ultrasonic sensor to read water level in the dam. SMS messages are sent to nearby residents to warn them of the opening of the dam gate. An alarm also sounds before the eventual opening of the dam gate. The system was tested with a mini setup to represent a dam. All components of the system performed effectively and in a timely manner. Such a system will ensure the operation of dam gates is safe and automated. Also, it ensures residents are well aware of the opening of dam gates when the dam is full to ensure residents evacuate quickly and safely.
\end{abstract}

\section{INTRODUCTION}

Dams are man-made or artificial barriers usually built across a stream channel to store water. [1] Dams have become a very essential part of electricity generation to humans. There is basically very little work one can do without being connected to electricity. Hydroelectricity is electricity produced from hydropower. Commonly hydroelectric power plant uses a dam on a river to store water in a reservoir. Water released from the reservoir flows through a turbine, spinning it, which in turn activates a generator to produce electricity. But hydroelectric power doesn't always need a large dam. Some hydroelectric power plants just use a small canal to direct the river water through a turbine. [2]

Hydropower generated $16.6 \%$ of the world's total electricity and $70 \%$ of all renewable electricity in the year 2015 and was expected to rise about $3.1 \%$ per year for the next 25 years. [3] The cost of producing hydroelectricity is relatively low, making it a very competitive source of renewable electricity. [4] The importance of hydropower is apparent. Apart from hydroelectricity, dams can also be used to reduce floods, for industrial use, for irrigation purposes, and many more. But even with these many benefits, if the release of water from dams is not well managed and organized it can lead to destruction of the dam itself and more devastatingly, the loss of lives and property.
Over the years, dams have been constructed to help produce power, to reduce floods and also, provide water for other activities such as irrigation, human consumption, industrial use and aquaculture. This has been carried out to some extent such that dams are typically provided with spillway systems to safely pass a broad range of flows over, around or through the dam. [1]

Various materials are used for dam construction such as rocks, earth, timber, concrete, steel or a combination of these materials. However, most dams are constructed using earth or combinations of earth and other materials. Spillways are commonly constructed of non-erosive materials such as concrete or rock. A spillway with control mechanism is almost always provided for release of waters during excess flood inflows. Releases of water may also be carried out by control devices provided in channels in the body of the dam and tunnels. [5]

The main objective of this research is to design a microprocessor based automated dam shutter system capable of sensing water levels and with GSM communication ability, purposely for dispensing emergency messages to the appropriate authority and nearby inhabitants notifying them of the opening of the dam. The rest of the paper is organised as follows: Section 2 presents related works, section 3 presents the proposed model, section 4 presents the operation of the system, section 5 presents the testing and section 6 concludes the paper. 


\section{RELATED WORKS}

Ganesh et. al [5] proposed a system which automatically operates the opening and closing of shutters to control the level of water in a dam using a microcontroller as well as sending warning messages to alert people nearby about the opening of the dam. Their system has two water levels, L1 which is the lower level and L2, the upper level. Sensors are placed at each level to detect the level of water as it rises or decreases in the dam. A GSM module is used to alert people living downstream via SMS messages. RF modules are used to communicate with loud speakers to sound alarms as well. When the water level in the dam rises above L1, the GSM module is triggered and sends warning messages to residents nearby. When the level rises above L2, the alarm circuit is activated and sounds the alarm. The RF transmitter sends a signal to receivers connected to loud speakers located downstream to sound the alarm for inhabitants living around to be aware of the impending opening of the dam for them to move to safe locations. The microcontroller then activates the gate controls to automatically open the gates. When the water level falls below L1, the gates are closed automatically. The system operates effectively, however, it lacks a display to determine the actual water level of the dam. Due to this, if there is a failure of one of the sensors or components, operators will not be able to determine if the level of water is at an unsafe level to be able to manually open or close the gates.

Saranya et. al [6] presented an automated gate control and monitoring system using GSM technology. A float sensor is fixed in the dam and it is responsible for sensing the level of water in the dam. When the level of water reaches $90 \%$, a signal is sent to a microcontroller to open the dam gates and when the level of water reduces to $50 \%$, the gates are closed. A GSM module is connected to the microcontroller which sends SMS messages to officials when the level of water is unsafe. The system also incorporates a $\mathrm{pH}$ sensor as well as a temperature sensor. The system however, does not automatically warn inhabitants nearby when the water level of the dam increases and the gates have to be opened. Officials of the dam have to do this manually. This could cause a problem for inhabitants if there is a sudden rise in the water level before officials can warn the inhabitants.

Rajendran et. al [7] proposed an Arduino microcontroller-based system to control movement of dam gates automatically. The system uses a level sensor attached to the reservoir to determine the level of water in the dam. An RF transmitter transmits the level of water in the dam to a computer via an RF receiver to display. The system operates with three gates. As the level of water increases, the gates open till all the gates are open. The system however, does not have a warning system before the gates are opened.

The system proposed in [5] only detects water at certain level, i.e. L1, L2 and L3 and cannot determine the actual level of water in the dam. The system proposed in [6] requires a manual alert to residents in the event of high level of water in the dam which requires the dam to be opened. The system proposed in [7] does not detect the exact level of water and also does not have a warning system before the dam gates are opened. The existing systems reviewed also do not have data storage capability to be able to log activities of the system for record keeping and further analysis.

\section{SYSTEM DESIGN}

The proposed model is made up of a microcontroller, an ultrasonic sensor, a rotor, GSM module, LCD screen, LEDs and a buzzer. The microcontroller is the central component of the system. The entire function of the system is programmed onto it. It processes all the data received from the peripheral devices for decision making. The ultrasonic sensor is used to sense the level of water. The operation of an ultrasonic sensor is such that it transmits a sound pulse that reflects from the surface of the water and then measures the time it takes for the echo to return to determine the level at which the water is. The sensor is a key component of the system since its operation determines how the effective the entire system will be. A failure in the sensor will mean the system will not be able to determine the level of water in the dam and cause the rest of the system to malfunction. The rotor controls the motions of the dam gate. The GSM module sends warning messages to nearby inhabitants of a possible dam gate opening for them to prepare and get to safety before disaster strikes. The LCD screen displays the level of water in the dam at all times to ensure the dam operator is fully aware of the water level in the dam. The LEDs serve as a visual aid for the dam operator for the different levels of water at which action is taken by the system. The buzzer sounds the alarm as a final warning before the dam gates are opened. There is also a log file kept on a computer to record the activities of the system. Data stored in the log file include the water level, time of dam gate opening or closing in the event they have to be opened and the time at which the warning SMS messages are sent. This data stored helps to record the various major operations of the system for record keeping and also for further analysis if needed. Figure 1 shows a block diagram of the system with the interconnected components.

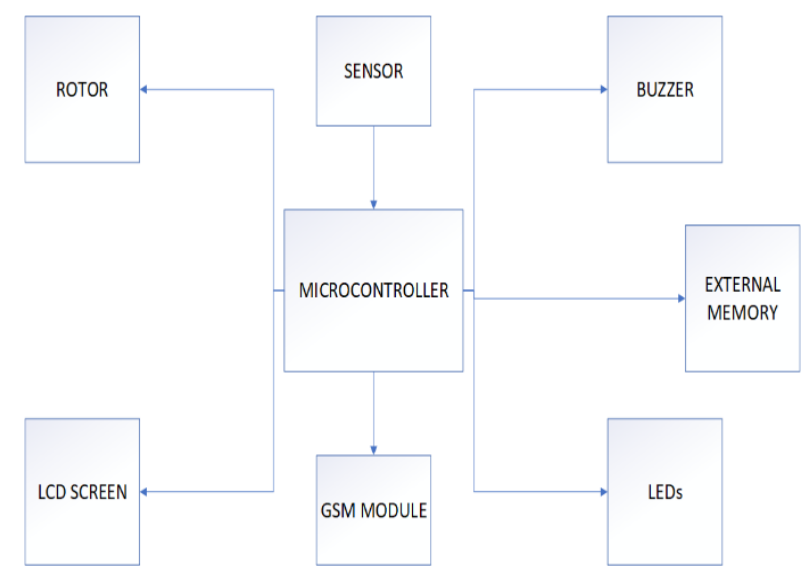

Figure 1. Dam Shutter System Block Diagram

\section{SYSTEM OPERATION}

There are three pre-set levels of water programmed into the system and action is taken at each level. Level 1 is the first level which shows the water level is low. Level 2 indicates that the 
water is about midway of the dam and preparations should be made for the possibility of opening the dam gates. Level 3 shows that the dam is almost full and the dam gates have to be opened to release water.

At system initialisation, the sensor reads the level of water in the dam. The water level is displayed on the LCD screen. The LCD screen updates as the water level changes. If the water level is below level 1, the system performs no action. If the water level reaches level 1, a green LED lights up to indicate the water is at the first level. At this level, if the dam gate is closed, no further action is taken, but if the dam gates are open, the microcontroller sends a command to close the dam gates. When the water reaches level 2, a yellow LED lights up and the GSM module is activated to send warning messages to mobile numbers captured in the system. When the water level reaches level 3, a red LED lights up and the buzzer sounds the alarm to warn of the impending opening of the dam gates. After a set amount of time, the rotor is activated and the dam gates are opened. At each level, a record is kept of the time at which the water reached that level. Also, the times at which the dam gates opened or closed are recorded. Figure 2 shows a flow chart of the operation of the system. Figure 3 shows a use case diagram of the system. The dam operator is able to see the water level of the dam in real-time as well as the LED indicators. Along with the nearby inhabitants, the dam operator receives the warning message and hears the buzzer sound the alarm before the dam gates are opened.

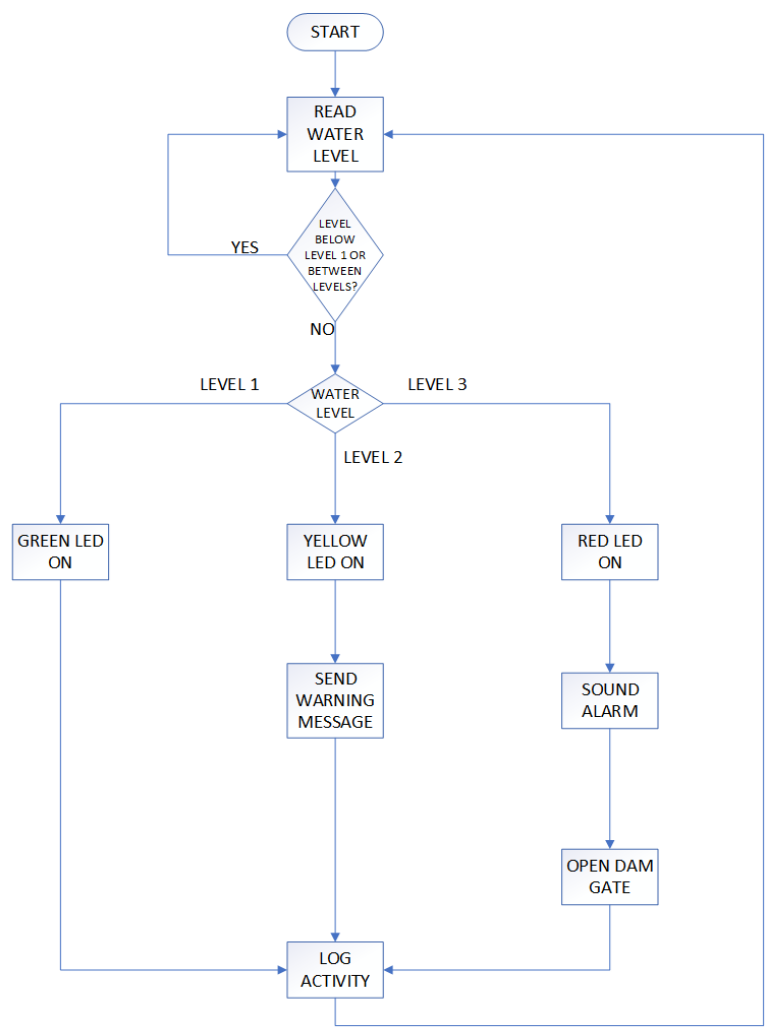

Figure 2. Dam Shutter System Work Flow

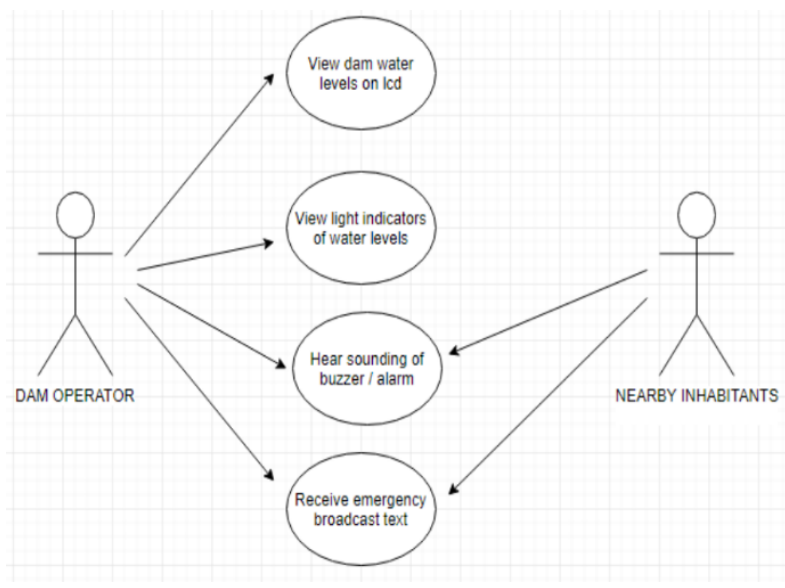

Figure 3. Dam Shutter System Use Case Diagram

\section{RESULTS AND DISCUSSION}

To test how effective the system operates, a mini dam prototype was set up. The ultrasonic sensor was calibrated for the mini dam and placed at the top to determine the level of water. A DC motor was used to mimic the control of opening and closing of the dam gates. Different phone numbers were input into the system for the broadcast message test. A buzzer was used to sound the alarm before the dam gates open.

The three water levels were set in the system. The first was at 7 inches, the second at 11 inches and the third at 16inches out of 20inches. The three LEDs were connected to the microcontroller to give an easy visual indication of the level at which the water was, aside the water level displaying on the LCD screen.

The mini dam was filled with water gradually. At the first level, the green LED lighted up to indicate the level of water was low. At the second level, the yellow LED lighted up and warning messages were sent to the phone numbers stored in the system. At the third level, the red LED lighted up and the buzzer sounded an alarm. After a period of time, the motor began to spin, indicating the dam gates were being opened. The system was found to perform as expected, although there was a slight delay before the broadcast messages were delivered. This could be attributed to weak network signal. Further testing was done in a location with better network signal and messages were delivered without delay. Figures 4 and 5 show the prototype setup of the system. 


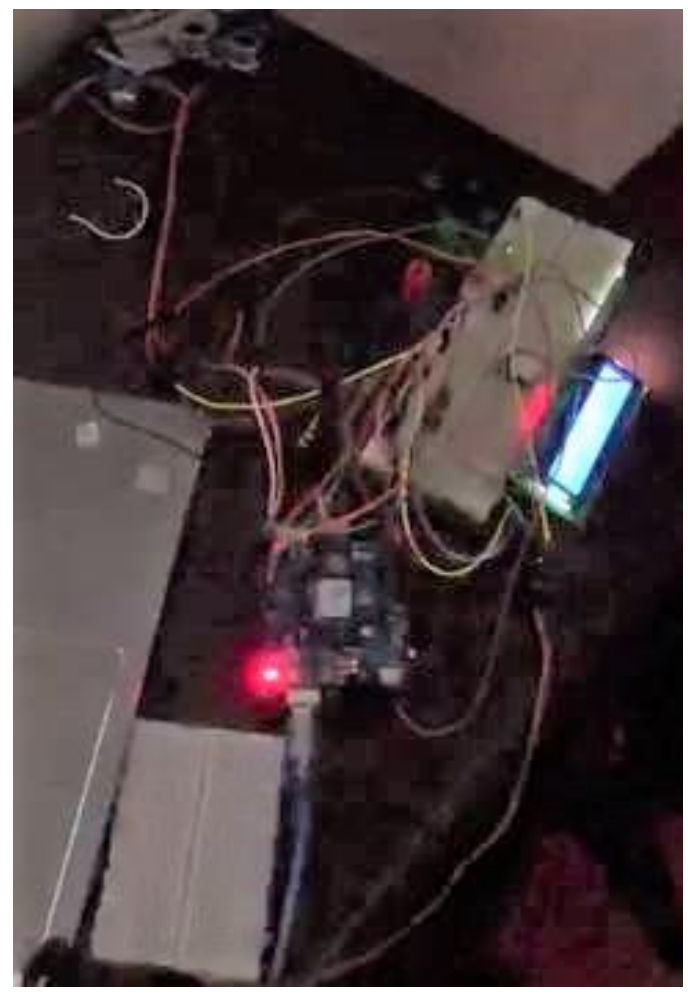

Figure 4. Dam Shutter Prototype Setup

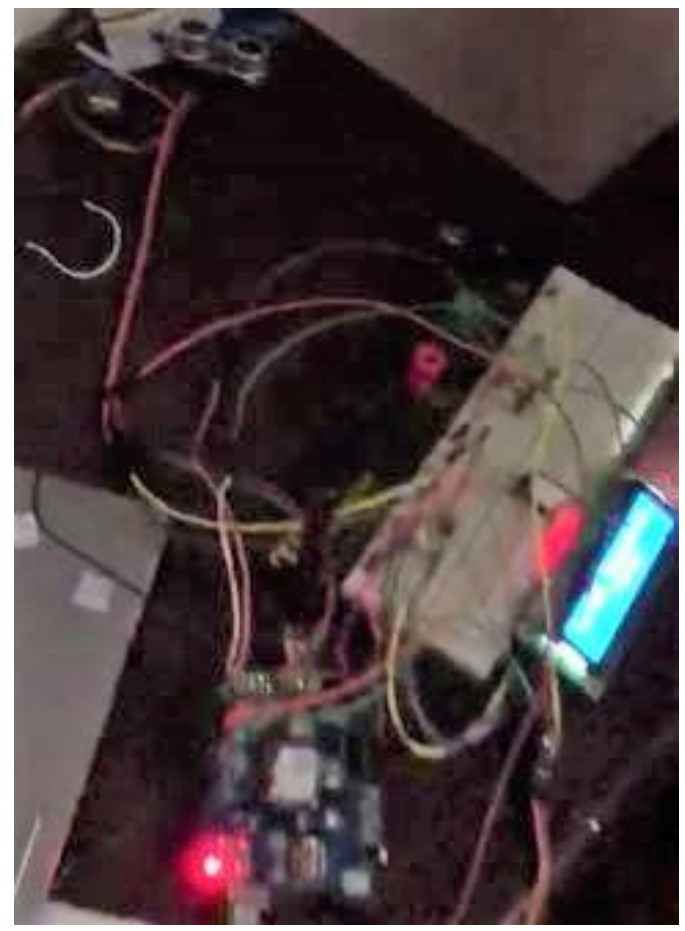

Figure 5. Dam Shutter Prototype Test Run operations and this was achieved using a GSM module. The decision to send these broadcasts through GSM was influenced by its ready availability, its reliability and relative cheapness. The overall inclusion of components and the design of our proposed ADS system adds the various functionalities we aimed to provide in order to make dam operation of gates more efficient, easier and safer.

With these functionalities effectively implemented, there is a high probability that our system will indeed make dam operation of gates more efficient, easier and safer to the community. This would go a long way in reducing the risk of loss of lives and property and in extreme situations, damage to the dam's overall structure.

Future works will include a trial with different sensors in use and a comparison to determine the most accurate of these sensors, the most cost-effective as well as the sensor which requires the least maintenance for dam operations.

\section{REFERENCES}

[1] Prashant Bhardwaj, Yogendra Singh Rajawat, Satyaprakash Rajput, Satyaveer Singh Narvariya, Laxmi Narayan, "Automatic Dam Shutter Senses the Water Level And Control The Dam Door Using Servo Motor", Proceedings of 4th SARC-IRF International Conference, New Delhi, India, 27th April. 2014, ISBN: 978-9384209-08-7.

[2] Renewable Energy World. Hydropower Technology and Types of Hydroelectric Power Plants [Internet]. Available from: https://www.renewableenergyworld.com/hydropower/tech.html [Accessed: July 20, 2018]

[3] Ken Casey, "The Coming Chaos: Fossil Fuel Depletion and Global Warming”. Chapter 9, pp. 69.

[4] Worldwatch Institute. Use and Capacity of Global Hydropower Increases [Internet]. Available from: http://www.worldwatch.org/node/9527 [Accessed: July 20, 2018]

[5] Ganesh M, Sreekanth P K, Sooraj Suresh Kumar, "Auto Controlled DAM with SMS Warning System", in Asian Journal of Engineering and Technology (ISSN: $2321-2462$ ) Volume 03 - Issue 04, Special issue for ICETTAS'15, 2015.

[6] Saranya B, Sanju S, Santhiya L.P, Sandhiya G, Palanivel D, "Automatic Gate Control and Monitoring the Water Reservoir using GSM Technology", in International Journal of Research in Electronics, Volume 03, Issue 03 2016, ISSN: 2349-252X, 2016. [7] V. Rajendran, J. Shilpa, S. Veeravalavan, and M. Anbarasan, "Dam Automation Using Arduino", in International Journal of Innovation and Scientific Research ISSN 2351-8014 Vol. 30 No. 3 May 2017, pp. 364-369.

\section{CONCLUSIONS}

In this paper, we have presented a design for an Automated Dam Shutter that would effectively tackle the issue of operating dam gates manually whilst warning nearby inhabitants. We selected components that would assure proper management and operations of dam gates. Apart from this, we proposed the inclusion of a device that would broadcast emergency texts to the necessary parties as an additional feature to the process of dam 